\title{
Variation in the expression of cell envelope proteins of coagulase-negative staphylococci cultured under iron-restricted conditions in human peritoneal dialysate
}

\author{
Mark H. Wilcox, ${ }^{1,2}$ Paul Williams, ${ }^{1 *}$ David G. E. Smith, ${ }^{1}$ Belinda Modun, ${ }^{1}$ \\ ROGER G. FinCH ${ }^{2}$ and STEPHEN P. DENYER ${ }^{1} \dagger$ \\ ${ }^{1}$ Department of Pharmaceutical Sciences, University of Nottingham, University Park, Nottingham NG7 2RD, UK \\ ${ }^{2}$ Department of Microbial Diseases, City Hospital, Nottingham NG5 IPB, UK
}

(Received 24 April 1991; accepted 24 July 1991)

\begin{abstract}
Strains of coagulase-negative staphylococci (CNS), including Staphylococcus epidermidis, S. hominis, S. warnerii, $S$. simulans, $S$. capitis, S. haemolyticus and $S$. saprophyticus, were isolated from patients with continuousambulatory-peritoneal-dialysis-related peritonitis. The cell wall and cytoplasmic membrane protein profiles of CNS strains cultured in either nutrient broth (NB) or pooled human peritoneal dialysate (HPD) were compared. Some interspecies variation in both the wall and membrane protein profiles was noted. However, the cell wall protein profiles of HPD-grown CNS strains differed markedly from those cultured in NB. Growth in HPD resulted in a marked reduction in the total number of cell-wall-associated proteins but up to three antigenically related proteins in the 40-56 kDa range, depending on the species, predominated. Growth in HPD also resulted in the induction of two iron-repressible cytoplasmic membrane proteins (IRMPs) of 32 and $36 \mathrm{kDa}$ in $S$. epidermidis. Other CNS strains only appeared to express a single IRMP, which varied in molecular mass from 32 to $36 \mathrm{kDa}$. Whilst the IRMP in these CNS strains showed considerable antigenic homology with the $32 \mathrm{kDa}$ IRMP, the $S$. warneri IRMP showed cross-reactivity with both the 32 and $36 \mathrm{kDa}$ IRMPs of $S$. epidermidis. Immunoblotting experiments revealed that whilst the CNS cell wall proteins were poorly immunogenic, the IRMPs were the immunodominant CNS protein antigens, reacting strongly with antibodies present in HPD. This finding provides evidence to suggest that the IRMPs are expressed in vivo during infection.
\end{abstract}

\section{Introduction}

Coagulase-negative staphylococci (CNS) are most commonly encountered as commensal bacteria on the skin of humans and animals (Kloos, 1990; Noble, 1990). Until relatively recently, they were regarded as contaminants of clinical samples rather than as potential pathogens. However, they have emerged as a significant problem in medical-device-related infections associated with indwelling catheters, prosthetic heart valves and cerebrospinal fluid shunts (Gemmel, 1986; Pulverer et al., 1987; Gemmel \& McCartney, 1990; Peters et al.,

$\dagger$ Present address: Department of Pharmacy, Brighton Polytechnic, Moulsecombe, Brighton BN2 4GJ, UK.

\footnotetext{
Abbreviations: CNS, coagulase-negative staphylococci; CAPD, continuous ambulatory peritoneal dialysis; NB, nutrient broth; HPD, human peritoneal dialysate; IRMPs, iron-repressible membrane proteins.
}

1990). In patients undergoing treatment for renal failure by continuous ambulatory peritoneal dialysis (CAPD), the CNS, and in particular $S$. epidermidis, are the predominant cause of peritonitis where they have been isolated in up to $60 \%$ of cases (Bint et al., 1987; Spencer, 1988; Wilcox et al., 1991). In addition, many CAPD patients suffer persistent or recurrent staphylococcal peritonitis.

The virulence determinants of the CNS have not been well characterized, although the pathogenesis of CNS infections has been related to bacterial adherence to host tissues and polymer implant surfaces (Christensen, 1987; Pulverer et al., 1987; Peters et al., 1990). The molecular basis of these interactions has not yet been fully established, but scanning electron microscopy has revealed that following the initial adherence events, the CNS form biofilms on the surface of implants (Bayston \& Penny, 1972; Peters et al., 1981; Marrie et al., 1983). Individual staphylococcal colonies become enmeshed in 
a loosely associated extracellular 'slime' which is thought to confer protection against host phagocytic cells (Gray et al., 1984). In CAPD peritonitis, the staphylococci appear to gain entry via the CAPD catheter, and rapidly establish themselves as an adherent biofilm on the catheter and/or peritoneal membrane surface (Spencer, 1988). Under these conditions, infection develops rapidly despite the apparently low levels of planktonic bacteria and the readily demonstrable host cellular immune response.

The emergence of the CNS as significant pathogens has aroused much interest in both the differentiation of CNS isolates and the characterization of candidate virulence determinants. A variety of schemes based on whole cell protein profiles and employing SDS-PAGE and immunoblotting techniques have been evaluated for both typing and taxonomic purposes (Clink \& Pennington, 1987; Burnie \& Lee, 1988). Such studies, however, provide no information on the nature or localization of specific protein antigens which may contribute to pathogenicity. Clearly more information could be obtained by fractionation of staphylococcal cell envelopes. Cheung \& Fischetti (1988) described a method based on the digestion of $S$. aureus with lysostaphin in a hypertonic raffinose solution which permits the separation of cell wall and cytoplasmic membrane components. This technique has been adapted and used to examine the cell wall and cytoplasmic membrane protein profiles of $S$. epidermidis strains from CAPD peritonitis (Denyer et al., 1990a; $1990 b$; Smith et al., 1991). In these studies, S. epidermidis strains were grown under conditions designed to mimic growth in vivo within the dialysed peritoneum, i.e. in pooled human dialysate (HPD) incubated in air enriched with $5 \%$ carbon dioxide. Although bacteria do not grow in commercial peritoneal dialysis solutions, the solutions are modified during dialysis and become capable of supporting bacterial growth (Verbrugh et al., 1984; Williams et al., 1988). The cell wall and cytoplasmic membrane protein profiles of $S$. epidermidis cultured under these conditions differed markedly from those of nutrient-broth (NB)-grown cells (Williams et al., 1988; Smith et al., 1991). In particular, many cell wall proteins were repressed, and two iron-regulated cytoplasmic membrane proteins (IRMPs) of 32 and $36 \mathrm{kDa}$ were induced in the HPD grown staphylococci (Williams et al., 1988; Denyer et al., 1990b; Smith et al., 1991). The molecular masses and antigenic homology of these IRMPs were highly conserved in $S$. epidermidis isolates from CAPD peritonitis. In addition, they were found to be the immunodominant $S$. epidermidis cell envelope antigens; sera and HPD fluid from CAPD patients, as well as normal human sera, contained antibodies directed against these proteins (Smith et al., 1991). In the present paper we have extended these investigations to other CNS species associated with CAPD-related peritonitis.

\section{Methods}

Bacterial strains and growth conditions. CNS strains were isolated from the dialysis fluid of CAPD patients with peritonitis attending the Renal Unit, City Hospital, Nottingham. Staphylococci were speciated using the API Staph (API, Basingstoke, UK) and by the Central Public Health Laboratory, Colindale Av., London, UK as: S. epidermidis (strain 901$) ; S$. hominis (80 and 120);S. warnerii (79 and 105); $S$. simulans (62 and 115); S. capitis (75); S. haemolyticus (95) and $S$. saprophyticus (907). Two further strains were identified as $S$. warnerii/capitis (9) and $S$. hominis/haemolyticus (10). Bacteria were cultured statically in NB (Oxoid) or in sterile, antibiotic-free pooled $\mathrm{HPD}$ at $37^{\circ} \mathrm{C}$ in an atmosphere of $95 \%$ air, $5 \% \mathrm{CO}_{2}$. For some experiments, HPD was enriched with iron by adding $20 \mu \mathrm{M}-\mathrm{FeSO}_{4}$.

Fractionation of staphylococci. Cell wall and cytoplasmic membrane proteins were prepared as described previously (Denyer et al., 1990a; Smith et al., 1991) following an adaptation of the method of Cheung \& Fischetti (1988). Briefly, staphylococci were resuspended in $0.6 \mathrm{ml}$ of digestion buffer $\left[30 \%(\mathrm{w} / \mathrm{v})\right.$ raffinose, $1 \mathrm{mg} \mathrm{m}^{-1}$ benzamidine, $0.5 \mathrm{mg} \mathrm{ml}^{-1}$ PMSF in Tris/HCl buffered saline ( $\left.\mathrm{pH} 7.4\right)$ containing $100 \mu \mathrm{g}$ lysostaphin] and incubated for $60 \mathrm{~min}$ at $37^{\circ} \mathrm{C}$. Protoplasts were removed by centrifugation and the supernatant containing the cell wall proteins was stored at $-20^{\circ} \mathrm{C}$ until required. Cytoplasmic membranes were collected by centrifugation after sonication and lysis of the protoplast suspensions.

$S D S-P A G E$. Cell wall and cytoplasmic membrane proteins were separated on $12.5 \%$ SDS-PAGE gels. Approximately $10 \mu \mathrm{g}$ protein was loaded per lane. Following electrophoresis, gels were either fixed and stained with Coomassie Brilliant Blue R250 or electrophoretically transferred to nitrocellulose.

Preparation of antisera. Monospecific polyclonal antisera were raised against the denatured, gel-purified 32 and $36 \mathrm{kDa}$ IRMPs isolated from S. epidermidis strain 901 as described previously (Smith et al., 1991). Antiserum was also raised against whole-cell antigens of $S$. epidermidis 901 following a modification of the method of Burnie et al. (1989). Briefly, staphylococci cultured on chocolate blood agar were resuspended in sterile PBS (120 mM- NaCl, $\left.10 \mathrm{~mm}-\mathrm{NaH}_{2} \mathrm{PO}_{4}, \mathrm{pH} 7.4\right)$ and sonicated in an ice bath for $10 \mathrm{~min}$. Whole cells were removed by centrifugation. The supernatant had its protein content adjusted to $50 \mu \mathrm{g} \mathrm{ml}^{-1}$ and was then mixed $1: 1$ with Freund's incomplete adjuvant. Antisera was raised in New Zealand White rabbits using three subcutaneous injections of $30 \mu \mathrm{g}$ protein at intervals of $21 \mathrm{~d}$. Hyperimmune sera was collected $14 \mathrm{~d}$ after the final inoculation.

Immunoblotting. Nitrocellulose immunoblots were incubated with the following range of probes: (i) monospecific polyclonal rabbit antisera raised as described previously (Smith et al., 1991) against either the $32 \mathrm{kDa}$ or the $36 \mathrm{kDa}$ IRMPs; (ii) hyperimmune rabbit sera raised against sonicated whole $S$. epidermidis 901 and (iii) pooled sterile HPD from the same pool used for bacterial culture. Nitrocellulose membranes were incubated in antibody solutions for either $4 \mathrm{~h}$ (rabbit antisera, diluted 1:400) or $18 \mathrm{~h}$ (HPD; undiluted). Bound antibodies were detected using protein A-peroxidase conjugate (Sigma). Reactive bands were visualized with a $25 \mu \mathrm{g} \mathrm{ml}^{-1}$ solution of 4-chloronaphthol containing $0.01 \%(\mathrm{v} / \mathrm{v})$ hydrogen peroxide. The molecular masses of reactive bands were estimated following counter-staining of nitrocellulose membranes with Ponceau S $(0.5 \%$ in $1 \%$ acetic acid). 


\section{Results}

Variation in the expression of CNS cell wall and cytoplasmic membrane proteins

The cell wall and cytoplasmic membrane protein profiles of representative strains of each of the CNS species used in this study and prepared from NB grown cells are shown in Fig. 1. These gels reveal that the CNS cell wall contains a large variety of different proteins. In addition, whilst many proteins of similar molecular mass are shared by the different CNS species, each isolate appears to possess cell wall proteins which contribute to a unique protein profile. Similarly, the cytoplasmic membranes of these CNS isolates can be differentiated on the basis of protein profile (Fig. $1 b$ ).

Fig. 2 shows an SDS-PAGE gel of the cell wall proteins of CNS strains grown in HPD. Compared with NB-grown staphylococci, a marked reduction in the total number of wall proteins was observed in all CNS strains. In each strain, at least two wall proteins were present at high concentrations, although they varied in molecular mass from 40 to $56 \mathrm{kDa}$ depending on the species. Growth of $S$. epidermidis strain 901 in HPD resulted in the induction of two novel cytoplasmic membrane proteins of 32 and $36 \mathrm{kDa}$ which are repressed in bacteria cultured in HPD containing excess added ferric iron or after growth in NB (compare Fig. $3 a$ lane 12 with lanes 12 and 6 in Figs $3 b$ and $1 b$, respectively). In other CNS species at least one iron-repressible cytoplasmic protein of between 32 and $36 \mathrm{kDa}$ was observed (Fig. $3 a$ ) which could be repressed by addition of excess iron (Fig. $3 b$ ). With the exception of a $105 \mathrm{kDa}$ protein in $S$. warneri (Fig. 2, lane 3) and a $130 \mathrm{kDa}$ protein in S. epidermidis (Fig. 2, lane 12), the iron content of HPD did not influence the expression of cell wall proteins (data not shown).

\section{Antigenic cross-reactivity between the IRMPs of $S$. epidermidis and those of other CNS species}

Antisera raised against the purified 32 and $36 \mathrm{kDa}$ IRMPs of $S$. epidermidis strain 901 were used to probe immunoblots of the cell membrane proteins of CNS strains cultured in HPD (Fig. 4). Anti-32-kDa sera reacted strongly with a single protein in each of the CNS examined. The reactive band varied in molecular mass from $32 \mathrm{kDa}$ in S. epidermidis (lane 12), S. hominis (lanes 6 and 7), and $S$. haemolyticus (lane 8 ), to $35 \mathrm{kDa}$ in $S$. simulans (lanes 9 and 10). Two reactive proteins appeared to be present in both $S$. simulans strains; a strongly cross-reactive band of $34 \mathrm{kDa}$, and a slightly less (a)

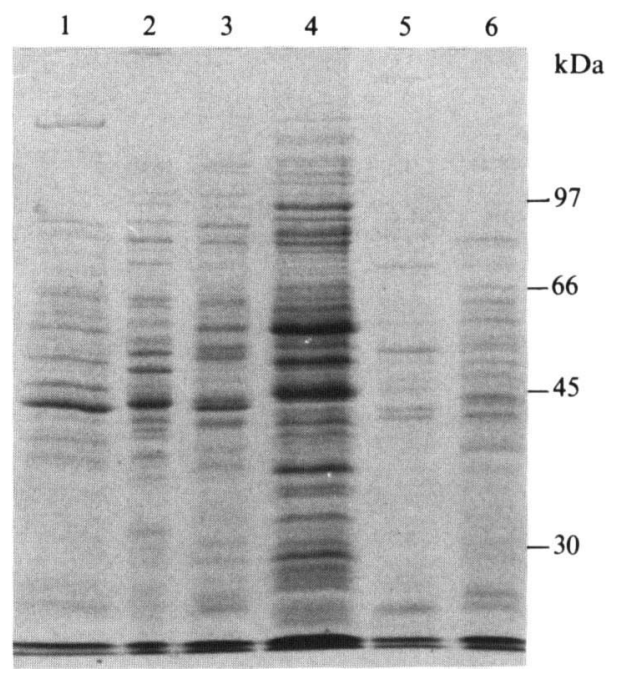

(b)

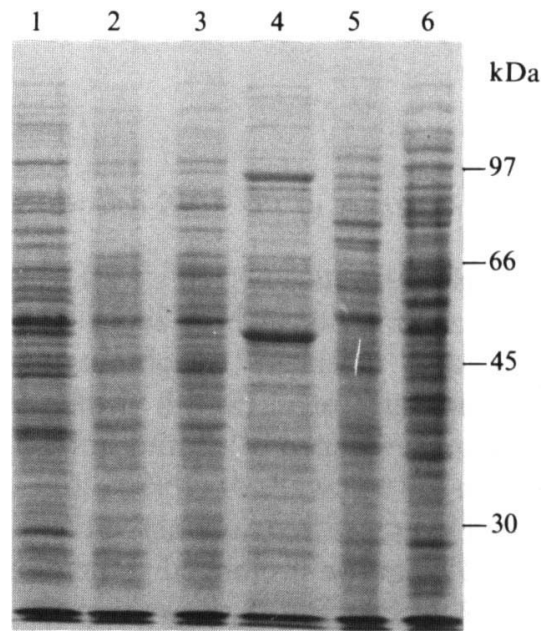

Fig. 1. (a) SDS-PAGE profiles of cell wall proteins prepared from CNS strains cultured in NB. S. warneri 105 (lane 1), S. hominis 120 (lane 2), $S$. haemolyticus 95 (lane 3), S. simulans 62 (lane 4), S. saprophyticus 907 (lane 5) and $S$. epidermidis 901 (lane 6). (b) SDS-PAGE profiles of cytoplasmic membrane proteins prepared from CNS strains cultured in nutrient broth. $S$. warneri 105 (lane 1), S. hominis 120 (lane 2), $S$. haemolyticus 95 (lane 3), S. simulans 62 (lane 4), S. saprophyticus 907 (lane 5) and $S$. epidermidis 901 (lane 6).

cross-reactive band of $35 \mathrm{kDa}$. The anti-36-kDa sera (Fig. $4 b$ ) cross-reacts strongly only with $S$. warneri/capitis (lane 1), S. warneri (lanes 2 and 3 ) and $S$. simulans (lanes 9 and 10). Little reactivity was observed with either antiserum when used to probe the cell membranes of staphylococci cultured in HPD containing excess iron or in NB (data not shown). 


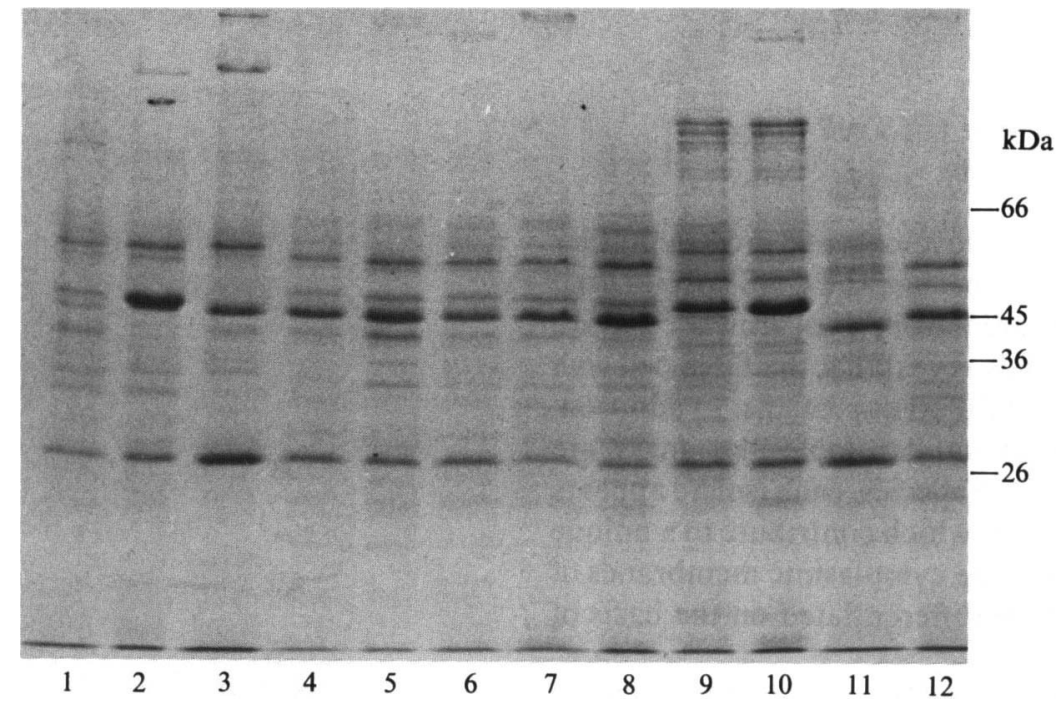

Fig. 2. SDS-PAGE profiles of the cell wall proteins from CNS strains cultured in pooled HPD. $S$ warneri/capitis 9 (lane 1); $S$. warneri strains 105 and 79 (lanes 2 and 3); S. capitis 75 (lane 4); S. hominis/haemolyticus 10 (lane 5); S. hominis strains 80 and 120 (lanes 6 and 7 ), S. haemolyticus 95 (lane 8), S. simulans strains 62 and 115 (lanes 9 and 10), S. saprophyticus 907 (lane 11) and S. epidermidis 901 (lane 12).

\section{Antigenic cross-reactivity of the CNS cell wall proteins}

The major HPD-induced cell wall proteins of $S$. epidermidis have previously been reported to be poorly immunogenic and attempts to obtain monospecific antisera were not successful (Smith et al., 1991). In an attempt to obtain evidence of shared antigenic protein determinants in the cell walls of CNS strains cultured in HPD, antisera were raised against an antigen preparation derived from the prolonged sonication of whole $S$. epidermidis 901 cells. Fig. 5 shows that the antiserum reacted with several 901 cell wall proteins (lane 12). In each of the other CNS strains examined, cross-reactions were observed with at least one cell wall protein and in most strains at least one of the major HPD-induced wall proteins reacted (Fig. 5, lanes 1-11). However, for the majority of CNS isolates examined, the overall wall antigen profile was similar although minor inter- and intra-species variation was observed.

\section{Humoral immune response to CNS cell wall and cytoplasmic membrane proteins}

Immunoblots of the cell wall (Fig. $6 a$ ) and cytoplasmic membrane proteins (Fig. $6 b$ ) of CNS strains cultured in HPD were probed with HPD to determine whether any of these antigens were recognized by immunoglobulins present in the pooled dialysate.
Relatively weak antibody responses to a small number of cell wall proteins were observed (Fig. $6 a$ ). For 7 of the CNS isolates evaluated, including $S$. warneri, $S$. capitis, $S$. hominis, and $S$. haemolyticus (Fig. $6 a$, lanes 2-8), the antigenic pattern was similar, in that two proteins of approximately 32 and $60 \mathrm{kDa}$ molecular mass reacted. The remaining CNS strains differed from this pattern in that the $S$. warneri/capitis strain 9 (lane 1) showed multiple reactive bands, the $S$. simulans strains (lanes 9 and 10) expressed strongly reactive bands in the $80-88 \mathrm{kDa}$ region, and $S$. saprophyticus (lane 11) and $S$. epidermidis (lane 12) isolates produced unique antigenic profiles. In addition, in all strains, at least one protein in the $32-36 \mathrm{kDa}$ range reacted with antibodies present in the dialysate. These proteins appeared to be the IRMPs, since no reaction was observed in this region of an immunoblot of wall proteins prepared from the same CNS strains cultured in HPD to which excess $\mathrm{Fe}^{3+}$ had been added (data not shown). Since these IRMPs appear to be highly immunogenic, their presence in the cell wall fractions either reflects: (i) a small amount of cytoplasmic membrane contaminating the cell wall preparations or (ii) that the IRMPs are associated with both cytoplasmic membrane and cell wall fractions although to a lesser extent with the latter.

Despite the large number of CNS cytoplasmic membrane proteins, Fig. 6(b) shows that, apart from $S$. warneri/capitis strain 9 (lane 1) and $S$. epidermidis 
(a)

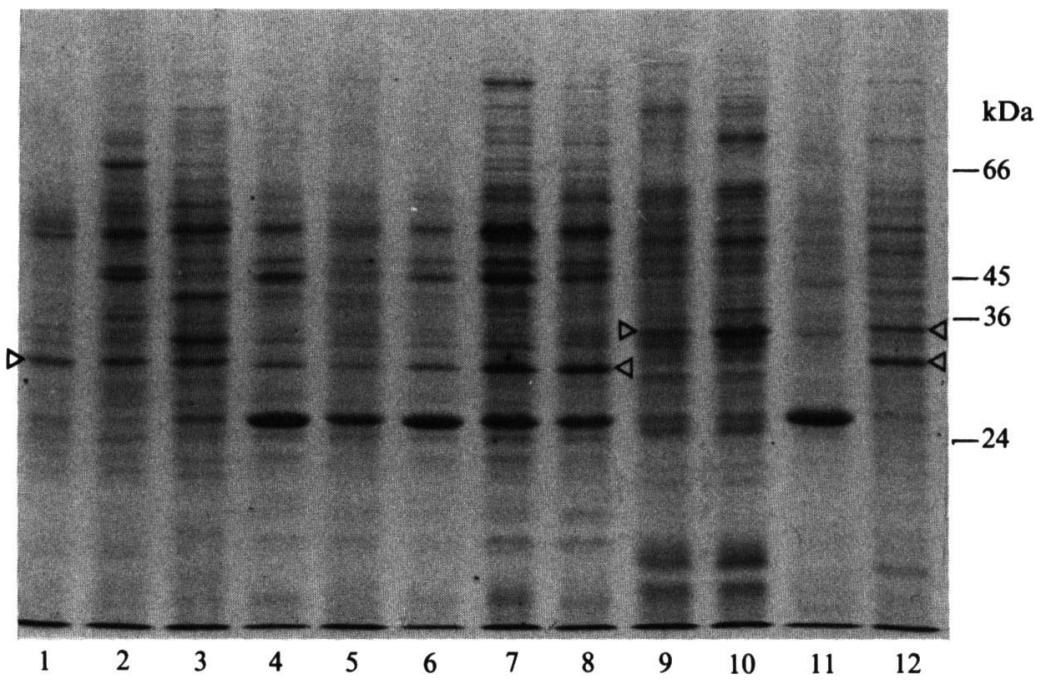

(b)

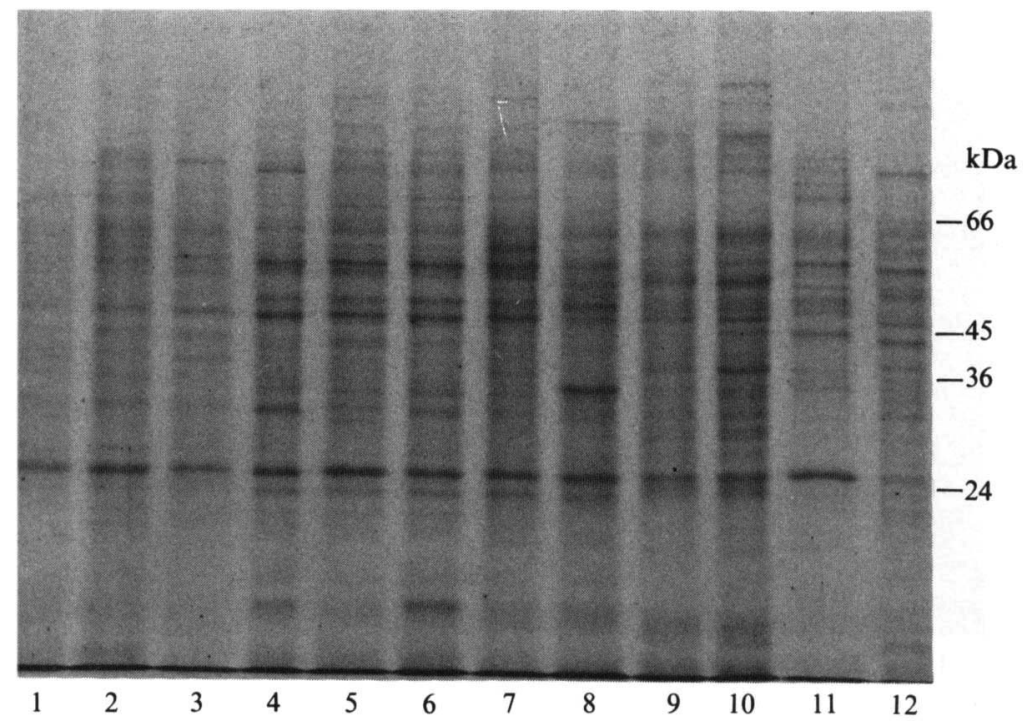

Fig 3. SDS-PAGE profiles of the cytoplasmic membrane proteins prepared from CNS strains cultured in (a) HPD and (b) HPD to which excess $\mathrm{Fe}^{3+}$ had been added; $S$. warneri/capitis 9 (lane 1); S. warneri strains 105 and 79 (lanes 2 and 3 ); $S$. capitis 75 (lane 4);S. hominis/haemolyticus 10 (lane 5); S. hominis strains 80 and 120 (lanes 6 and 7); S. haemolyticus 95 (lane 8); S. simulans strains 62 and 115 (lanes 9 and 10); S. saprophyticus 907 (lane 11) and S. epidermidis 901 (lane 12). In (a), arrowheads mark positions of IRMPs.

strain 901 (lane 12), only one major antigen reacts with immunoglobulins present in HPD, i.e. depending on the species, an IRMP of $32-36 \mathrm{kDa}$ (lanes 2-10). In $S$. epidermidis (lane 12), both the 32 and $36 \mathrm{kDa}$ IRMPs react whilst many different $S$. warneri/capitis antigens (lane 1), including the $32 \mathrm{kDa}$ IRMP, are visualized on the immunoblot.

\section{Discussion}

Commercial peritoneal dialysis fluids used in the management of end-stage renal failure by CAPD contain glucose and sodium lactate together with magnesium, calcium and sodium chlorides. They do not support bacterial growth until enriched with a plasma 'ultra- 
(a)

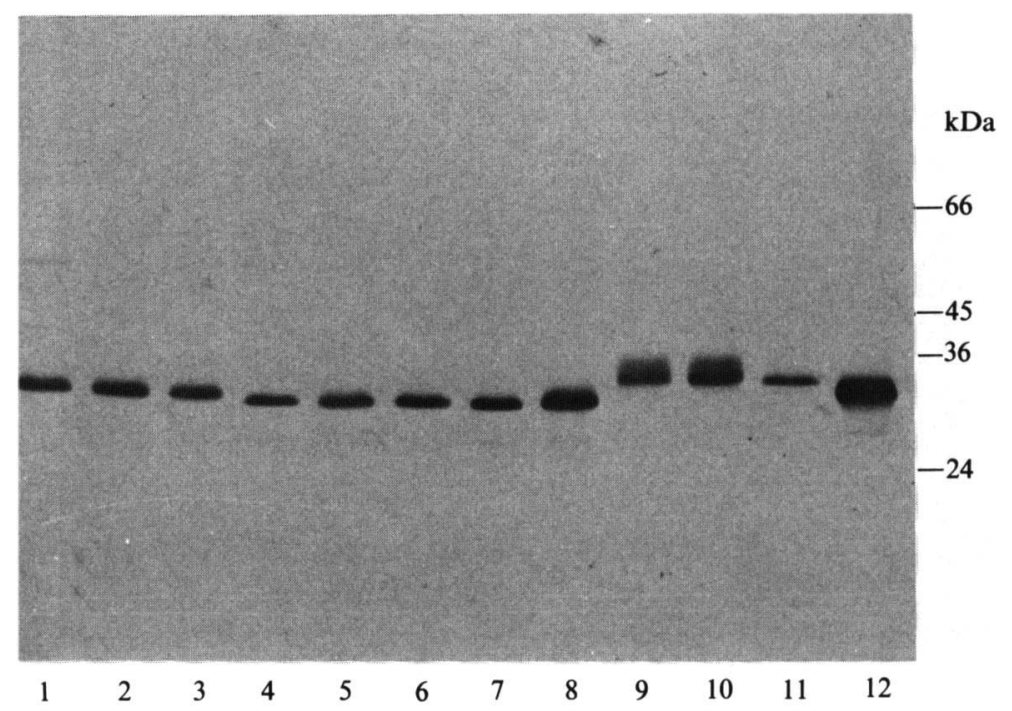

(b)

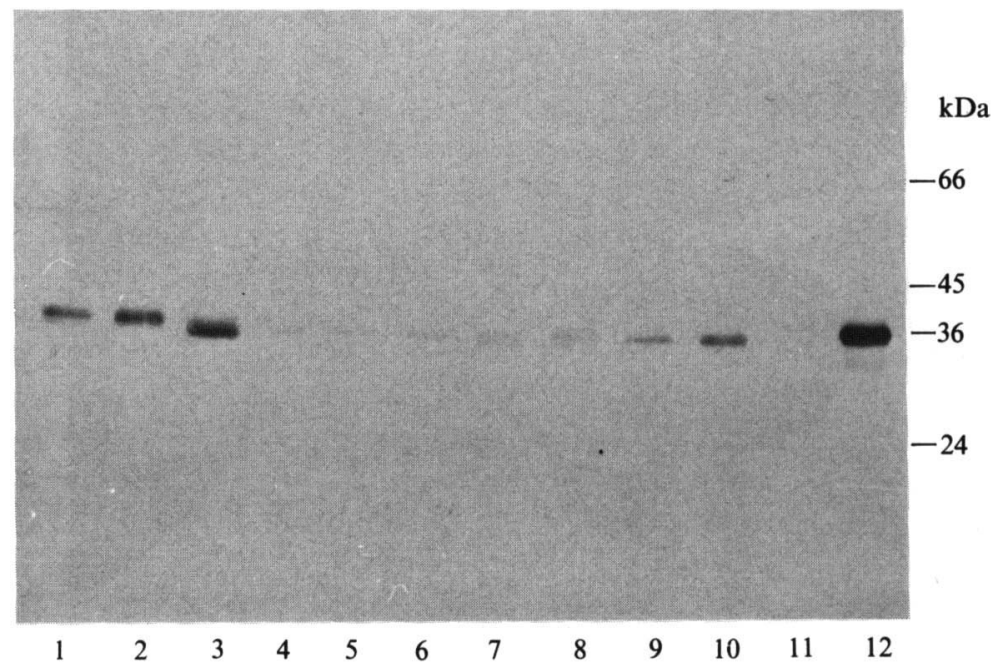

Fig 4. (a) Immunoblot showing the reactions of monospecific polyclonal antisera raised against the purified $32 \mathrm{kDa}$ IRMP of $S$. epidermidis 901 with cytoplasmic membranes prepared from 12 CNS strains cultured in HPD. Lanes correspond to those listed in Fig. 3. (b) Immunoblot showing the reactions of monospecific polyclonal antisera raised against the purified $36 \mathrm{kDa}$ IRMP of $S$. epidermidis 901 with cytoplasmic membranes prepared from 12 CNS strains cultured in HPD. Lanes correspond to those listed in Fig. 3.

filtrate' during dialysis (Verbrugh et al., 1984; Williams et al., 1988). This modified dialysate (HPD), however, precipitates during incubation at $37^{\circ} \mathrm{C}$ in air with the loss of salts and proteins. Precipitation can be prevented by incubating HPD in air enriched with $5 \%$ carbon dioxide, gaseous conditions which more closely resemble those found physiologically (Wilcox et al., 1990). CNS strains can therefore be grown under conditions which simulate those encountered within the dialysed periton- eum. Much evidence exists to indicate that bacteria are constantly sensing their environment and adjusting to it (Brown \& Williams, 1985; Williams, 1988; Griffiths, 1989). Studies of CNS isolates cultured in HPD may thus aid our understanding of the in vivo expression of virulence determinants and the pathogenesis of peritonitis. Information on the nature of the molecular interactions between staphylococcal cell envelope components and the CAPD host would be of particular value. 


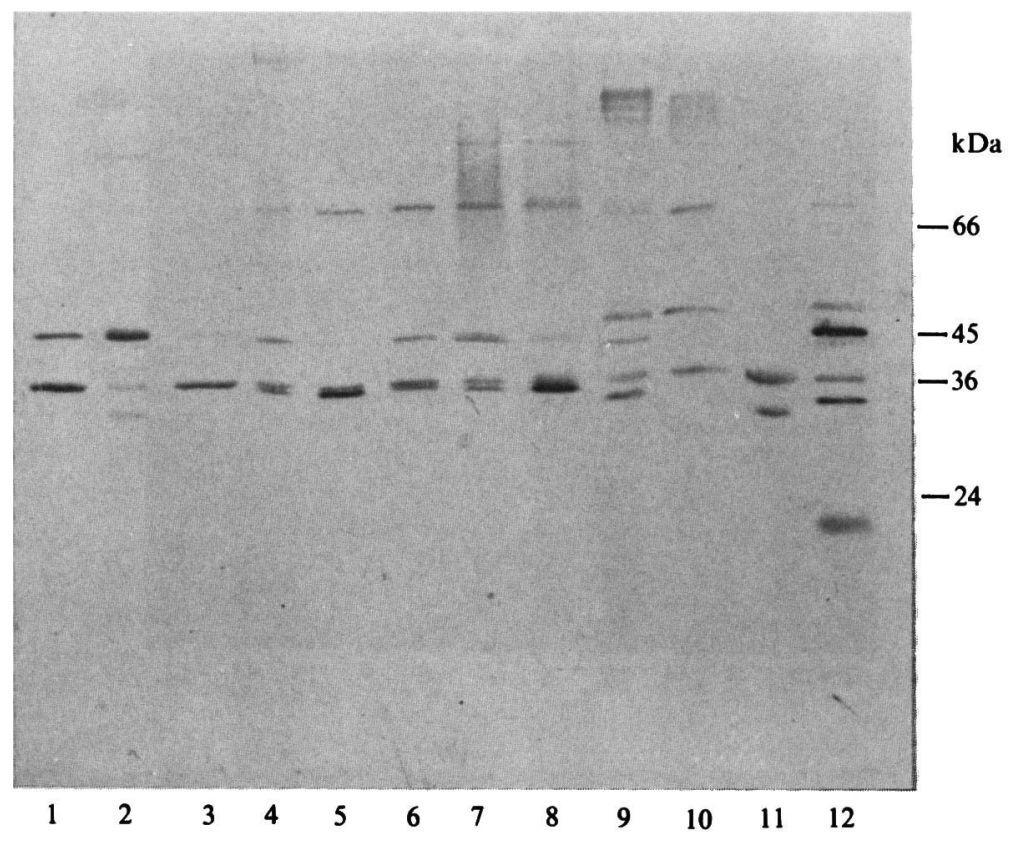

Fig 5. Immunoblot showing the reactions of the hyperimmune sera prepared after prolonged sonication of whole $S$. epidermidis cells with the cell wall proteins of 12 CNS strains cultured in HPD. Lanes correspond those listed in Fig. 3.

However, in contrast to the Gram-negative bacteria, there is relatively little data on the function and phenotypic plasticity of Gram-positive cell envelopes, especially with regard to proteins. This may reflect, in part, the difficulties of separating staphylococcal wall from cytoplasmic membrane proteins. By extracting cell wall proteins using lysostaphin in a protoplast-stabilizing medium, Cheung \& Fischetti (1988) observed that growth on a solid medium influenced the expression of cell wall proteins in $S$. aureus. Surface proteins ranging from $120-220 \mathrm{kDa}$, which were repressed during growth in liquid media, were induced by growing the organism on the surface of the same media solidified with agar. Apart from protein A, which binds immunoglobulins via a non-immune mechanism, $S$. aureus cell walls are also known to contain proteins which bind other host proteins including fibronectin, fibrinogen and collagen (Foster et al., 1990; Boden \& Flock, 1990). In $S$. epidermidis, carbon dioxide tension has been reported to influence the expression of both cell wall and cytoplasmic membrane proteins in NB-grown organisms (Denyer et al., 1990a). Growth in HPD has also been shown to exert a profound effect on the cell wall proteins of $S$. epidermidis strains isolated from CAPD peritonitis (Smith et al., 1991). HPD-grown S. epidermidis lacked many of the proteins present in the cell wall of NB-grown staphylococci. Although the cell wall proteins of NB grown CNS show some intra-species variation, the data shown in the present paper reveal that they respond similarly to the environmental conditions imposed by culture in HPD. This reduction in the expression of many cell wall proteins may therefore constitute a common response amongst the CNS to growth in a stressful environment such as that encountered during infection within the dialysed peritoneum. The cell walls of twelve different $S$. epidermidis isolates grown in HPD have previously been shown to contain three major common proteins of 42, 48 and $54 \mathrm{kDa}$ (Smith et al., 1991). These may be related to the major 37,41 and $51 \mathrm{kDa}$ proteins reported to be present in the cell walls of tryptic-soybroth-grown $S$. epidermidis by Patrick et al. (1990). However, the HPD-induced proteins are not surfaceexposed and so are unlikely to contribute to the interactions between bacteria and host tissues or catheter surfaces.

Growth of the CNS in HPD also resulted in the expression of one or two iron-repressible cytoplasmic membrane proteins in the $32-36 \mathrm{kDa}$ range. These proteins were poorly expressed in NB-grown cells but could be induced by the addition of a synthetic iron chelator such as ethylene-diamine di-o-(hydroxyphenylacetic acid) (Smith et al., 1991). Since HPD not only contains less than $0.5 \mu \mathrm{M}-\mathrm{Fe}^{3+}$ but also contains the serum iron-binding glycoprotein transferrin, HPD con- 
(a)

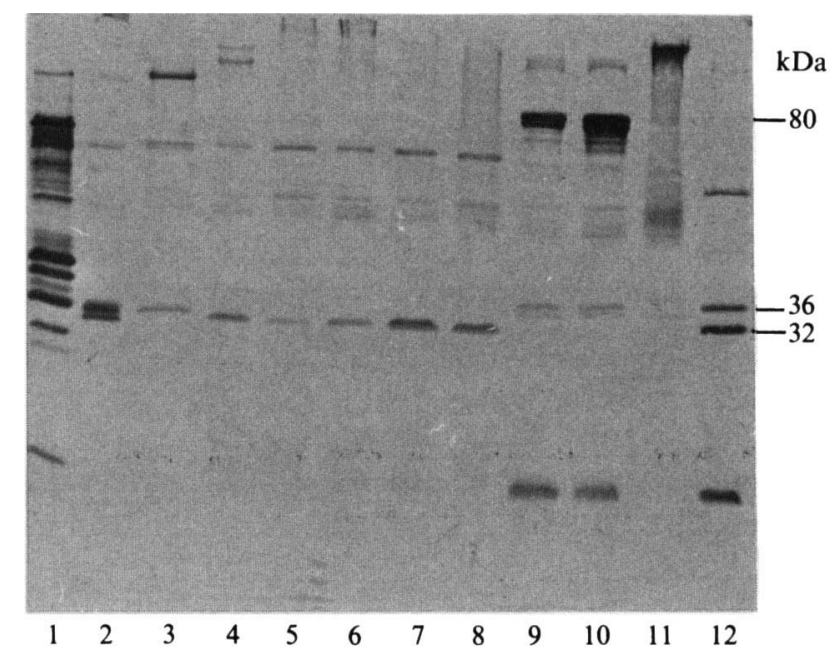

(b)

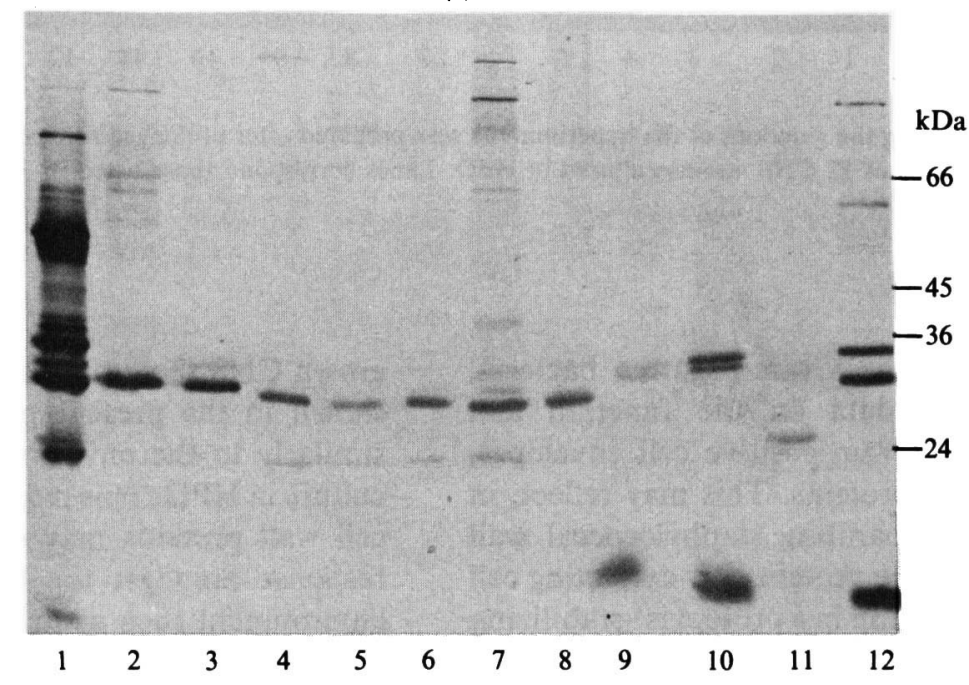

Fig 6. Immunoblot showing the reactions of antibodies in pooled HPD with (a) cell wall proteins and $(b)$ cytoplasmic membrane proteins of 12 CNS strains cultured in HPD. Lanes correspond to those listed in Fig. 3.

stitutes a severely iron-restricted growth environment (Wallaeys et al., 1986; Williams et al., 1988). Gramnegative bacteria generally respond to iron stress by derepressing high-affinity iron-scavenging systems based on low-molecular-mass iron chelators (siderophores) and their corresponding outer-membrane protein receptors (Griffiths, 1987; Williams, 1988). Certain pathogens, notably Neisseria meningitidis and Haemophilus influenzae employ a siderophore-independent iron-acquisition system based on the direct interaction between a bacterial surface receptor and transferrin (Morton \& Williams, 1990).

Little information is available on the mechanisms by which staphylococci acquire iron in iron-restricted environments. CNS strains isolated from bovine intramammary infections have been reported to bind bovine lactoferrin (Naidu et al., 1990) although no evidence was presented to indicate whether this interaction represented a mechanism for iron-acquisition. Two putative staphylococcal siderophores termed staphyloferrin A and B have, however, been recently described (Meiwes et al., 1990; Konetschny-rapp et al., 1990). Staphyloferrin A has been isolated from $S$. hyicus and chemically characterized as $N^{2}, N^{5}$-di(1-oxo-3-hydroxy-3,4-dicarboxybutyl)-D-ornithine, a compound which consists of two molecules of citric acid linked via an amide bond to D-ornithine (Konetschny-rapp et al., 1990). Staphyloferrin $\mathrm{A}$ is produced by both $S$. aureus and a variety of 
CNS strains, including $S$. epidermidis, $S$. haemolyticus, $S$. saprophyticus, $S$. simulans and $S$. warneri (Miewes et al., 1990). Some of these strains also produced staphyloferrin B. Although the precise mechanism by which ferric staphyloferrin $\mathrm{A}$ is taken up into the cell has not been elucidated, it appears to be an active transport process (Konetschny-rapp et al., 1990). In common with Gramnegative siderophore-based systems, such a mechanism will probably involve specific iron-regulated siderophore receptor proteins. Since the Gram-positive cell wall is unlikely to prevent access of low-molecular-mass compounds to the cytoplasmic membrane (Williams, 1988), it is tempting to speculate that the $32-36 \mathrm{kDa}$ IRMPs of the CNS function in siderophore-mediated iron transport. In addition, since these proteins show considerable antigenic homology, they may be involved in the transport of a common siderophore such as staphyloferrin A. In this respect, it is interesting to note that antisera raised against the $32 \mathrm{kDa} S$. epidermidis IRMP cross-reacts not only with an IRMP in each of the CNS species examined in this study, but also with a $32 \mathrm{kDa}$ membrane protein in $S$. aureus (Smith et al., 1991). The CNS isolates examined in this study all secrete iron chelators (unpublished observation) although they have not been chemically characterized. Further work is underway to characterize these putative siderophores and to establish their relationship to the $32-36 \mathrm{kDa}$ IRMPs.

Immunoblotting experiments using HPD, normal and CAPD patients' sera revealed the presence of antibodies to the 32 and $36 \mathrm{kDa}$ IRMPs of $S$. epidermidis (Williams et al., 1988; Smith et al., 1991). Similar results were obtained using HPD to probe the cytoplasmic membrane antigens of other CNS species. These experiments suggest that the IRMPs are the immunodominant CNS protein antigens and that they are expressed during growth in vivo. Interestingly, immunoblots of cell wall preparations probed with HPD also show some reaction with the IRMPs, implying that either the samples used are contaminated with small amounts of these highly immunogenic proteins or that a fraction of their population is cell-wall-associated. Ultrastructural studies are required to ascertain their location and distribution within the cell envelope.

In contrast to the IRMPs, the major $40-56 \mathrm{kDa}$ HPDinduced CNS cell wall antigens appeared to be relatively poorly immunogenic as revealed by their lack of reactivity in immunoblots probed with HPD. An exception to this was the $S$. warneri/capitis strain 9, the reactivity of which indicated the presence of high antibody titres in the pooled HPD, perhaps as a result of a recent clinical or sub-clinical infection by a related organism in one or more of the patients contributing to the HPD pool. Interestingly, the characteristic 80 and
$88 \mathrm{kDa}$ wall proteins of $S$. simulans and a $110 \mathrm{kDa}$ antigen from $S$. saprophyticus were also highly reactive. Whether these antigens are exposed at the cell surface and capable of interacting with host issues and defence mechanisms is currently under investigation.

The poor immunogenicity of $S$. epidermidis wall proteins following immunization of mice with whole bacterial cells has also been noted by Patrick et al. (1990). Interestingly, in contrast to the CNS, the cell wall proteins of $S$. aureus appear to be highly immunogenic (Smith et al., 1991). To determine whether any of the major HPD-induced CNS wall proteins were antigenically related, attempts were made to generate specific antibody responses in rabbits using the gelpurified 42, 48 and $54 \mathrm{kDa}$ proteins (unpublished data). As this technique failed to elicit significant antibody responses, an alternative approach was used. Antiserum was raised against an antigen preparation derived from the prolonged sonication of whole $S$. epidermidis cells. Using this antiserum, cross-reactivity between at least one of the major HPD-induced CNS cell wall proteins in each strain was observed, which suggests that they are antigenically and possibly functionally related. Further work is required to determine whether the poor antigenicity of CNS cell wall proteins contributes to the avoidance of host defence mechanisms within the dialysed peritoneum.

This work was supported by grants from the Welcome Trust and Roussel Laboratories Ltd, UK.

\section{References}

Bayston, R. \& Penny, S. R. (1972). Excessive production of mucoid substance in Staphylococcus SIIA : a possible factor in colonisation of Holter shunts. Developmental Medicine and Child Neurology 27, suppl., 25-28.

Bint, A. J., Finch, R. G., GoKal, R., GoldSMith, H. J., JUNOR, B. \& OLIVER, D. (1987). Diagnosis and management of peritonitis of CAPD. Report of a working party of the British Society for Antimicrobial Chemotherapy. Lancet ii, 845-849.

BODEN, M. \& FLOCK, J. I. (1990). Fibrinogen-binding proteins from Staphylococcus aureus. In Pathogenesis of Wound and Biomaterialassociated Infections, pp. 65-68. Edited by T. Wadstrom, I. Eliasson, I. Holder \& A. Ljungh. London: Springer-Verlag.

Brown, M. R. W. \& WilliaMs, P. (1985). The influence of environment on envelope properties affecting survival of bacteria in infections. Annual Reviews in Microbiology 39, 527-556.

BURNIE, J. P. \& LEE, W. (1988). A comparison of DNA and immunoblot fingerprinting of the SII biotype of coagulase-negative staphylococci. Epidemiology and Infection 101, 202-212.

Burnie, J. P., Matthews, R. C., Lee, W., \& Murdoch, D. (1989). A comparison of immunoblot and DNA restriction patterns in characterising methicillin-resistant isolates of Staphylococcus aureus. Journal of Medical Microbiology 29, 255-261.

Cheung, A. L. \& Fischetti, V. A. (1988). Variation in the expression of cell wall proteins of Staphylococcus aureus grown on solid and liquid media. Infection and Immunity 56, 1061-1065.

Christensen, G. D. (1987). The confusing and tenacious coagulasenegative staphylococci. Advances in Internal Medicine 32, 177-192. 
Clink, J. \& Pennington, T. H. (1987). Staphylococcal whole-cell polypeptide analysis; evaluation as a taxonomic and typing tool. Journal of Medical Microbiology 23, 41-44.

Denyer, S. P., Davies, M. C., Evans, J. A., Finch, R. G., Smith, D. G. E., Wilcox, M. H. \& Williams, P. (1990a). Influence of carbon dioxide on the surface characteristics and adherence potential of coagulase-negative staphylococci. Journal of Clinical Microbiology 28, 1813-1817.

Denyer, S. P., Davies, M. C., Evans, J. A., Finch, R. G., Smith, D. G. E., Wilcox, M. H. \& Williams, P. $(1990 b)$. Phenotypic changes in staphylococcal cell surface characteristics associated with growth in human peritoneal dialysis fluid. In Pathogenesis of Wound and Biomaterial-associated infections, pp. 453-458. Edited by $\mathrm{T}$. Wadstrom, I. Eliasson, I. Holder \& A. Ljungh. London: SpringerVerlag.

Foster, T. J., O'Reilly, M. \& Bramley, A. J. (1990). Genetic studies of Staphylococcus aureus virulence factors. In Pathogenesis of Wound and Biomaterial-associated Infections, pp. 453-458. Edited by $\mathrm{T}$. Wadstrom, I. Eliasson, I. Holder \& A. Ljungh. London: SpringerVerlag.

GEMmEL, C. G. (1986). Coagulase-negative staphylococci. Journal of Medical Microbiology 22, 285-295.

Gemmel, C. G. \& MCCARTNEY, A. C. (1990). Coagulase-negative staphylococci within the hospital environment. Reviews in Medical Microbiology 1, 213-218.

Gray, E. D., Peters, G., Verstegen, M., Regelmann, W. E. (1984). Effect of extracellular slime substance from Staphylococcus epidermidis on the human cellular immune response. Lancet i, 365-367.

GRIFFITHS, E. (1987). The iron-uptake systems of pathogenic bacteria. In Iron and Infection - Molecular, Physiological and Clinical Aspects, pp. 69-138. Edited by J. J. Bullen \& E. Griffiths. Chichester: John Wiley.

GRIFFITHS, E. (1989). The regulation of bacterial virulence genes by environmental signals. Current Opinion in Infectious Diseases 2, 819826.

KLoos, W. E. (1990). Systematics and natural history of staphylococci. 1. In Staphylococci. Edited by D. Jones, R. G. Board \& M. Sussman. Journal of Applied Bacteriology Symposium Supplement 19, 25S-37S.

KonetschNY-RAPP, S., Jung, G., Meiwes, J. \& ZAHNER, H. (1990). Staphyloferrin A: a structurally new siderophone from staphylococci. European Journal of Biochemistry 191, 65-74.

Marrie, T. J., Noble, M. A. \& Costerton, J. W. (1983). Examination of the morphology of bacteria adhering to peritoneal dialysis catheters by scanning and transmission electron microscopy. Journal of Clinical Microbiology, 18, 1388-1398.

Meiwes, J., Fielder, H.-P., HAaG, H., ZahNER, H., KonetschnyRAPP, S. \& JUNG, G. (1990). Isolation and characterization of staphyloferrin A, a compound with siderophore activity from Staphylococcus hyicus DSM 20459. FEMS Microbiology Letters 67, 201-206.

Morton, D. J. \& Williams, P. (1990). Siderophore-independent acquisition of transferrin-bound iron by Haemophilus influenzae type b. Journal of General Microbiology 136, 927-933.
Naidu, A. S., Miedzobrodzki, J., Andersson, M., Nilsson, L. E., FORSGREN, A. \& WATTS, J. L. (1990). Bovine lactoferrin binding to six species of coagulase-negative staphylococci isolated from bovine intramammary infections. Journal of Clinical Microbiology 28, 23122319.

NOBLE, W. C. (1990). Systematics and the natural history of staphylococci. 2. In Staphylococci. Edited by D. Jones, R. G. Board \& M. Sussman. Journal of Applied Bacteriology Symposium Supplement 19, 39S-48S.

Patrick, C. C., Plaunt, M. R., Sweet, S. M. \& Patrick, G. S. (1990). Defining Staphylococcus epidermidis cell wall proteins. Journal of Clinical Microbiology 28, 2757-2760.

Peters, G., LocCi, R., Pulverer, G. (1981). Microbial colonisation of prosthetic devices II. Scanning electron microscopy of naturally infected intravenous catheters. Zentralblatt fur Bakteriologie, Parasitologie, Infecktion und Hygiene, section B, 173, 293-299.

Peters, G., Schumacher-Perdreau \& Jansen, B. (1990). Staphylococcus epidermidis - a versatile pathogen. In Pathogenesis of Wound and Biomaterial-associated Infections, pp. 453-458. Edited by T. Wadstrom, I. Eliasson, I. Holder \& A. Ljungh. London: Springer-Verlag.

Pulverer, P., Quie, P. G. \& Peters, G. (1987). Pathogenicity and Clinical Significance of Coagulase-negative Staphylococci. Stuttgart: Gustav Fischer Verlag.

Smith, D. G. E., Wilcox, M. H., Williams, P., Finch, R. G. \& DENYER, S. P. (1991). Characterisation of cell envelope proteins of Staphylococcus epidermidis cultured in human peritoneal dialysate. Infection and Immunity, 59, 617-624.

SPENCER, R. C. (1988). Infections in continuous ambulatory peritoneal dialysis. Journal of Medical Microbiology 27, 1-9.

Verbrugh, H. A., Keane, W. F., Conroy, W. E. \& Peterson, P. K. (1984). Bacterial growth and killing in chronic ambulatory peritoneal dialysis fluids. Journal of Clinical Microbiology 20, 199-203.

Wallaeys, B., Cornelis, R., \& Lameire, N. (1986). The trace elements $\mathrm{Br}, \mathrm{Co}, \mathrm{Cr}, \mathrm{Cs}, \mathrm{Cu}, \mathrm{Fe}, \mathrm{Mn}, \mathrm{Rb}, \mathrm{Se}$ and $\mathrm{Zn}$ in serum, packed cells and dialysate of CAPD patients. In Frontiers in Peritoneal Dialysis. pp. 478-481. Edited by J. F. Maher and T. F. Winchester. New York: Field, Rich \& Associates.

Wilcox, M. H., Smith, D. G. E., Evans, J. A., Denyer, S. P., Finch, R. G. \& Williams, P. (1990). Influence of carbon dioxide on growth and antibiotic susceptibility of coagulase-negative staphylococci cultured in human peritoneal dialysate. Journal of Clinical Microbiology 28, 2183-2186.

WilcoX, M. H., Finch, R. G., Burden, R. P. \& Morgan, A. G (1991). Peritonitis complicating continuous ambulatory peritoneal dialysis in Nottingham: 1983-1988. Journal of Medical Microbiology 34, 137-141.

WILLIAMS, P. (1988). Role of the cell envelope in bacterial adaptation to growth in vivo in infections. Biochimie 70, 987-1011.

Williams, P., DeNYeR, S. P. \& FinCH, R. G. (1988). Protein antigens of Staphylococcus epidermidis grown under iron-restricted conditions in human peritoneal dialysate. FEMS Microbiology Letters 50, 29-33. 